\title{
Effects of reward schedule and chronological age on motor performance of mental retardates'
}

PETER WATSON, U. OF WESTERN ONTARIO, THOMAS J. RYAN, CARLETON U., OTTAWA ROBERT C. MGEWAH, U. OF WESTERN ONTARIO

Mentally retarded children in two age ranges were given $0 \%, 10 \%, 30 \%, 50 \%, 70 \%$ or $100 \%$ reward on a lever-pulling lask. Partial reward led to increasing response speed as a function of training, while speeds of the $0 \%$ and $100 \%$ groups did not change over blocks of trials. Chronological age had no effect on lever-pulling speeds.

Several studies with normal kindergarten children (e.g., Ryan \& Voorhoeve, 1966) have shown that partial reinforcement produces faster lever-pulling in a discrete-trial task than is the case for continuous (100\%) reward. The superiority of partial reward has been attributed to an increment in drive level as a result of nonreward-produced frustration (Amsel, 1958). Frustration theory has also been used to explain data acquired with retarded Ss; however, in two studies (Lobb, Moffitt, \& Gamlin, 1966; Moffitt \& Ryan, 1966) the partially- and continuously-rewarded groups did not differ in terms of response speed, whereas in another (Longstreth, 1966), they did. In the present study with retarded children, six reward schedules identical to those used by Ryan \& Voorhoeve (1966) were employed in order to determine the parametric relationship between response speeds and percentage of reinforcement. An additional variable of interest was chronological age (CA) of the Ss.

\section{Method}

The Ss were 112 mental retardates divided into young ( $N=51$; $C A X=135.3$ months; CA range $=94-$ 166 months) and old ( $N=61$; $\mathrm{CA} X=188.2$ months; CA range $=168-216$ months) groups which also differed, to a lesser extent, on mental age and IQ. Within each CA group, Ss were assigned randomly to one of six treatment groups which differed with respect to the percentage of reward received during testing. All Ss were given 60 trials on a lever-pulling apparatus similar to that described by Ryan \& Voorhoeve (1966) and were rewarded with a marble on either $0 \%, 10 \%, 30 \%, 50 \%, 70 \%$, or $100 \%$ of the trials. Ss were told that if they won enough marbles they could trade them for a small box of candy. Between each trial $E$ recorded starting time, from the onset of a stimulus light to the initial movement of the lever, and movement time, the time taken to pull the lever down through its 15-in. excursion, to the nearest .01 sec. Results

Starting and movement times were converted to speeds (1/t sec.) and combined into six blocks of 10 trials per block. The blocked starting and movement speeds were submitted to separate 6 by 2 by 6 analyses of variance, with percentage of reward and $\mathrm{CA}$ as between-Ss variables and trial blocks as the within-Ss variable. Since the starting and movement speed results are essentially similar, only those obtained for movement speed will be reported.

Significant effects were obtained for trial blocks $(F=22.68$, df $=5 / 500, p<.001)$ and for the interaction between blocks and percentage of reward $(F=2.74$, $\mathrm{df}=25 / 500, p<.001)$. All effects for CA were nonsignificant. In general, speeds increased over training. The blocks by schedule interaction (see Fig. 1) suggests that the increment in performance was restricted to the partial-reward groups. This suggestion was confirmed by a series of treatment by Ss analyses performed on each percentage group (collapsed across CA): significant increases as a function of blocks were shown by the 10\%, 30\%, 50\% (ps<.001), and $70 \%$ ( $<<.05$ ) groups. 2 The $0 \%$ and $100 \%$ groups did not change as training progressed.

In order to determine the relationship between asymptotic level of performance and percentage of reward, movement speeds on the sixth block were submitted to a simple-randomized analysis of variance and the resulting error term used to evaluate trend components in the means. Although the simple-randomized analysis indicated no significant differences among the asymptotic means, the subsequent trend analysis revealed a reliable quadratic component ( $F$

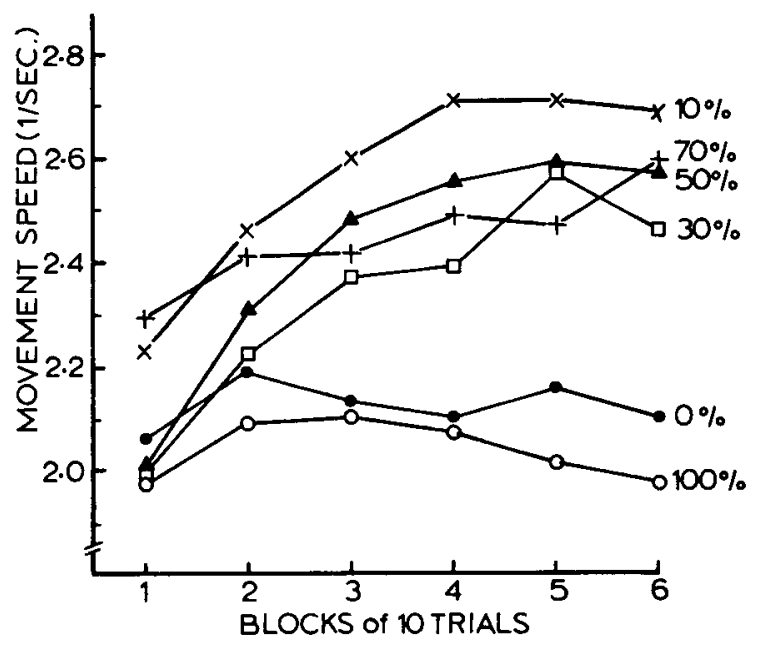

Fig. 1. Mean movement speed for six reinforcement groups as a function of six blocks of 10 trials. 
$=5.32, \mathrm{df}=1 / 106, \mathrm{p}<.05)$ which accounted for $72 \%$ of the variance among the means. Neither linear nor cubic trends were significant.

\section{Discussion}

The present results suggest that inconsistent reward produces increasingly faster performance relative to both consistent reward (100\%) and nonreward (0\%), in retarded as well as normal children. The relationship between percentage of reward and asymptotic pertormance, on the basis of the significant quadratic component among the means, can be described by an inverted U-shaped function, with slowest performance produced by $0 \%$ and $100 \%$ reward. This appears, in part, consistent with Ryan \& Voorhoeve's (1966) results, where a similar relationship was demonstrated. The present findings are less clear-cut, however, in that the asymptotic means did not differ significantly. Tentative support is thus provided for the notion that retardates are generally less responsive than normal children to nonreward (cf., Lobb et al, 1966; Moffitt \& Ryan, 1966). The absence of differential performance as a function of CA suggests that developmental factors have relatively little effect on responsiveness to nonreward, at least in the age ranges employed. Because
$\mathrm{CA}$ and mental age were to some degree confounded in the present study, this conclusion deserved further investigation.

\section{References}

Amsel, A. The role of frustrative nonreward in noncoptinuous reward situations. Psychol. Bull., 1958, 55, 102-119.

Lobb, H. O., Moffitt, A. R., \& Gamlin, P. Frustration and adaptation in relation to discrimination learning ability of mentally defective children. Amer. J. ment. Defic., 1966, 71, 256-265. Longstreth, L. E. Frustration and secondary reinforcement concepts as applied to human conditioning and extinction. Psychol. Monogr., 1966, 80, No. 11.

Moffitt, A. R., \& Ryan, T. J. The frustration effect in normal and retarded children under widely spaced trials. Univ. W. Ont. Res. Bull., 1966, No. 16.

Ryan, T. J., \& Voohoeve, A. C. A parametric investigation of reinforcement schedule and sex as related to acquisition and extinction of an instrumental response. J. exp. child Psychol., $1966,4,189-197$.

\section{Notes}

1. Financial support for this study was provided by Ontario Mental Health Grant No. 79, to the second author, and by the Ontario Department of Health through the Children's Psychiatric Research Institute, London, Canada. Watson's address: Department of Psychology, University of Western Ontario, London, Canada.

2. For starting speeds, the increment in performance shown by the $70 \%$ group was significant at the .06 level. 